\title{
Prominent contribution of Th1, Th17, and Tregs to the host response during M. neoaurum infection
}

\author{
C.F. Wang ${ }^{1}$, W.T. Yang ${ }^{1}$, L.M. Yue ${ }^{1}$, J.Y. Qiu ${ }^{1}$, L.J. Zhang ${ }^{1}$, C. Wang ${ }^{1,2}$, \\ X.Y. Jiang ${ }^{3}$ and A.D. Qian ${ }^{1,2}$ \\ ${ }^{1}$ College of Animal Science and Technology, Jilin Agricultural University, \\ Changchun, China \\ ${ }^{2}$ Key Laboratory of Animal Production, \\ Product Quality and Security Ministry of Education, Changchun, China \\ ${ }^{3}$ College of Life Sciences, Jilin Agricultural University, Changchun, China \\ Corresponding author: C.F. Wang \\ E-mail: wangchunfeng@jlau.edu.cn
}

Genet. Mol. Res. 15 (3): gmr.15038989

Received July 21, 2016

Accepted August 1, 2016

Published September 23, 2016

DOI http://dx.doi.org/10.4238/gmr.15038989

Copyright (C) 2016 The Authors. This is an open-access article distributed under the terms of the Creative Commons Attribution ShareAlike (CC BY-SA) 4.0 License.

ABSTRACT. Nontuberculous mycobacteria are ubiquitous in outside
environment and animals. As for nontuberculous mycobacteria
infection, there is only limited information in humans regarding infection
and the subsequent immune response, especially for Mycobacterium
neoaurum. Here, haematoxylin-eosin and Ziehl-Neelsen staining
were used to observe pathological changes and detect acid-fast bacilli
in organ samples in mouse model. Flow cytometry and quantitative
real-time polymerase chain reaction were performed to analyze the
contribution of Th1, Th17 and Tregs to the host immune response. $M$.
neoaurum caused chronic infection in mice, resulting in infiltrates with
large aggregates of inflammatory cells, especially macrophages, in lung

Genetics and Molecular Research 15 (3): gmr.15038989 
tissues. Our results indicated that $72 \%$ of CD4+ T cells appeared in the early days of infection, which was followed by a decrease to $47 \%$ by day 32 , and then a rise to $76 \%$ by day 56 . Moreover, we found higher frequency of IFN- $\gamma$-producing CD4+ T cells and elevated mRNA expression of the transcription factor T-bet in the lungs; however, we observed lower mRNA expression of the transcription factor ROR $\gamma \mathrm{t}$ and lower frequency of IL-17-producing CD4+ T cells. A transient relative decrease in the number of Treg cells was observed in the lungs; however, the number of Tregs did not change significantly between the first and last day following infection. Thus, M. neoaurum causes chronic infection in C57BL/6 mice, with Th1, Th17, and Tregs playing a prominent role in the host response. The present study may lay the basis for further studies on the mechanisms underlying infection with nontuberculous mycobacteria.

Key words: Nontuberculous mycobacteria; Mycobacterium neoaurum; Immune response; Th1; Th17; Treg

\section{INTRODUCTION}

Nontuberculous mycobacteria (NTM), also known as environmental mycobacteria or atypical mycobacteria, are ubiquitous in soil, water, dust, aerosol and in animals (Kazda et al., 2009; Kim et al., 2014); present high isolation rates; and are becoming an emerging cause of infectious diseases worldwide. NTM result mainly in skin and lymphoid tissue infection, as well as lung disease (Griffith et al., 2007). Many of these microorganisms are opportunistic pathogens, especially in cancer (Umehara et al., 2015), HIV (Ristola et al., 2015), and immunodeficient patients (Fowler and Mahlen, 2014; Henkle and Winthrop, 2015). In humans, NTM cause an important infectious disease, and the main risk factor is thought to be environmental exposure. Although an increasing number of studies are targeting the prevalence and distribution of NTM (Gcebe et al., 2013; Arrazuria et al., 2015), there has been only limited research on the host defense mechanisms against NTM.

There has been substantial research on NTM infection and immune response in humans, but not in wild animals or livestock. The main step in the immune response to Mycobacterium tuberculosis infection involves activation of effector CD4+ T helper 1 (Th1) cells (Flynn et al., 1993; Newport et al., 1996) and the subsequent production of cytokines, for example, interferon (IFN)- $\gamma$ and tumor necrosis factor (TNF)- $\alpha$.

Increasing evidence indicates that successful $M$. tuberculosis immunity relies not only on Th1 but also other T cell subsets (Goldsack and Kirman, 2007; Chen et al., 2012). Regulatory $\mathrm{T}$ (Treg) cells sustain peripheral tolerance, inhibit chronic infection, modulate the adaptive immune response (Sakaguchi et al., 2010), and can inhibit the activity of effector cells against intracellular pathogens (Shevach, 2009) including M. tuberculosis. Thus, Tregs may play an important role in limiting tissue damage during M. tuberculosis infection. However, Tregs are also responsible for delaying the initiation of an immune response against $M$. tuberculosis (Larson et al., 2013). In comparison, the contribution of T helper 17 (Th17) cells against $M$. tuberculosis infection is less well known, although interleukin (IL)-17 has been reported to effectively promote granuloma formation, limit bacterial growth, and generate other cytokines

Genetics and Molecular Research 15 (3): gmr.15038989 
such as IL-21 and IL-22 (Kolls and Lindén, 2004; Cooper, 2010).

The purpose of this research was to characterize the pathogenesis and immune response in C57BL/6 mice infected with $M$. neoaurum, and analyze the contribution of Th1, Th17, and Treg cells to the host response. These results will improve our understanding of mycobacterial and particularly $M$. neoaurum infection.

\section{MATERIAL AND METHODS}

\section{Mice}

Specific pathogen-free 6- to 8-week-old female C57BL/6 mice were supplied by Beijing HFK Bio-Technology Co., Ltd., China. Mice were bred on underpads in the Biosafety Level 3 biohazard facility at Jilin University. They were fed mouse chow and sterile water.

\section{Mycobacterium}

Mycobacteria were isolated from cattle submandibular lymph nodes and conserved in our laboratory. Based on BLAST analysis of $16 \mathrm{~S}$ rRNA and genome sequencing, the mycobacteria were identified as M. neoaurum. Middlebrook $7 \mathrm{H} 9$ medium with glycerol and Tween- 80 enrichment was used for cultivation of bacteria. The bacteria displayed a smooth, rod-shaped morphology.

\section{Mouse infection}

Mice were injected intraperitoneally with log-phase M. neoaurum ( $5 \times 10^{6}$ bacteria/ mouse) in $0.5 \mathrm{~mL}$ phosphate-buffered saline. Mice $(\mathrm{N}=5-6$ mice/group) were killed at different time-points after infection, and lung samples were collected. Bacterial titers were determined through serial dilutions of lung homogenates on Middlebrook 7H9 agar plates.

\section{Histopathology}

Lung samples were fixed in buffered formalin and pathological sections were made. We used haematoxylin-eosin and Ziehl-Neelsen staining plus methylene blue as counterstain, to observe pathological changes and detect acid-fast bacilli in organ samples.

\section{Quantitative real-time polymerase chain reaction (qPCR)}

Cytokines were quantified by qPCR. Lung samples were ground by mortar using liquid nitrogen. Total RNA was abstracted and reverse transcribed into cDNA. qPCR was performed using SYBR Premix Ex-Taq ${ }^{\mathrm{TM}}$. Negative controls were analyzed simultaneously and glyceraldehyde 3-phosphate dehydrogenase (Gapdh) was used for normalization.

\section{Lung cell digestion}

Small pieces of lungs were incubated with $500 \mu \mathrm{L}$ RPMI 1640 medium containing $0.5 \mathrm{mg} / \mathrm{mL}$ collagenase XI (Sigma-Aldrich, USA) and $50 \mu \mathrm{g} / \mathrm{mL}$ DNase I (Sigma-Aldrich) for

Genetics and Molecular Research 15 (3): gmr.15038989 
$90 \mathrm{~min}$ at $37^{\circ} \mathrm{C}$. Cells were then harvested by centrifugation at $2000 \mathrm{~g}$ at $4^{\circ} \mathrm{C}$ for $5 \mathrm{~min}$. Red blood cells were aliquoted into $500 \mu \mathrm{L}$ lysates, incubated at room temperature for $3 \mathrm{~min}$, and then harvested.

\section{Flow cytometric characterization of cell surface antigens}

Lung single-cells were stained with fluorophore-conjugated antibodies antiCD3e (clone 145-2C11), anti-CD4 (clone GK1.5) and anti-CD8 (clone 53-6.7) (BD Pharmingen). Flow cytometric detection was executed on an Accuri C6 flow cytometer (BD Biosciences, USA).

\section{Intracellular cytokine staining}

Isolated lung cells were stimulated for 4-5 $\mathrm{h}$ with phorbol 12-myristate 13-acetate (PMA) and ionomycin (Sigma-Aldrich), followed by monensin (BD Biosciences) treatment for the last $2-3 \mathrm{~h}$ of cultivation at $37^{\circ} \mathrm{C}$ and $5 \% \mathrm{CO}_{2}$. Stimulated lung cells were incubated with FITC-conjugated antibodies for CD4 (clone GK1.5), fixed and permeabilized with BD GolgiPlug (BD Biosciences), and incubated with anti-mouse IL-17-A-PE, IL-4-PE, or IFN- $\gamma$-PE (BD Biosciences) for $30 \mathrm{~min}$ at $4^{\circ} \mathrm{C}$. Finally, cells were washed, fixed with $1 \%$ PFA, and analyzed using an Accuri C6 flow cytometer. Results were expressed as percentages of positive cells.

\section{CD4+ Foxp3 Treg expression}

The proportion of CD4+ Foxp3+ lymphocytes in the lungs of M. neoaurum infected mice was determined. Isolated lung cells were incubated with anti-mouse CD4-FITC and rat anti-mouse Foxp3 IgG (MF23; BD Biosciences) antibodies for $30 \mathrm{~min}$, washed, and resuspended in RPMI 1640 before analysis.

\section{Statistical analysis}

Statistical analysis was implemented using SPSS 13.0 (SPSS, USA) and Prism5 (GraphPad, USA) software. Results are reported as means \pm standard deviation.

\section{RESULTS}

\section{Changes in bacterial load}

M. neoaurum induced a systemic, disseminated infection in intraperitoneally infected C57BL/6 mice. Bacterial load in the lungs increased gradually for the first 7-20 days and then returned to its initial value by day 56 (Figure 1).

\section{Histopathological changes}

On day 20 post infection, the lungs of infected mice were characterized by large numbers of bacteria, interstitial pneumonia (indicating an inflammatory response), irregular 
alveolar spaces, broader and thicker alveolar septa, expanded and engorged blood capillaries, absence of Langhans giant cells or granulomas, and emerging inflammatory infiltrates with large aggregates of inflammatory cells, especially macrophages (Figure 2). By day 32 and 44, the inflammatory reaction had weakened and by day 56 , the number of inflammatory cells was markedly reduced, while a few fibroblasts were seen to accumulate and proliferate in the alveolar septum. In addition, infected mice showed multiple intracellular acid-fast staining bacilli (Figure $2 b$ ).

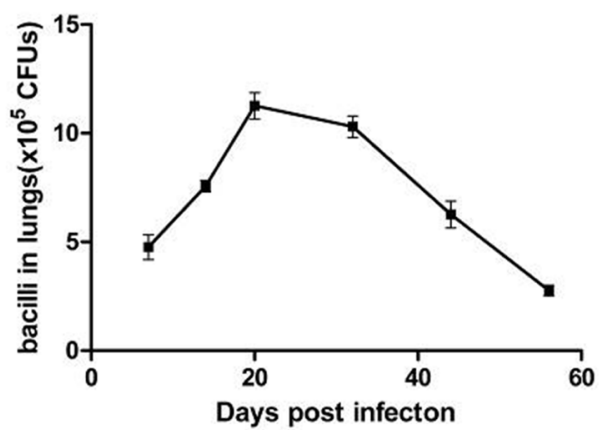

Figure 1. Bacterial counts (expressed as colony forming units, CFUs) in lungs from mice infected with Mycobacterium neoaurum. Samples were taken on day 7, 14, 20, 32, 44, and 56.

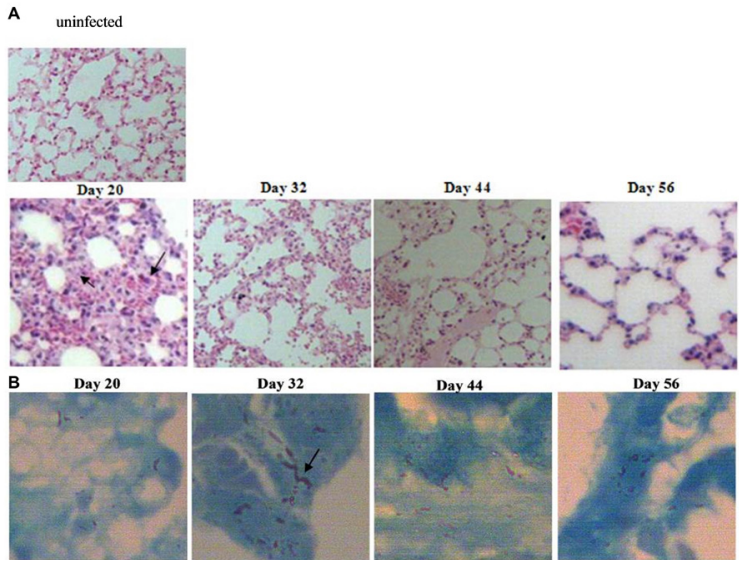

Figure 2. Histopathological analysis of lungs from $M$. neoaurum infected mice. A. Hematoxylin-eosin staining (100X) of lung tissue from uninfected mice (upper panel) and 20-56 days post infection (lower panels). Examples of broadening alveolar septum and inflammatory cells are indicated by arrows (day 20). B. Ziehl-Neelsen staining (800X magnification) of matched lung tissue sections 20-56 days post infection. Acid-fast bacilli appear red and are indicated by arrows (day 32 ).

\section{Analysis of mRNA expression in the lungs}

To better characterize cytokine secretion in infected mice, we evaluated transcription factors T-bet, Gata-3, ROR $\gamma$ t and Foxp3 in lung homogenates (Figure 3). Pulmonary T-bet concentrations increased gradually in infected mice for up to 56 days. In contrast, Gata-3 and ROR $\gamma t$ levels were high in the lungs of infected mice at day 20, but decreased thereafter $(\mathrm{P}<$

Genetics and Molecular Research 15 (3): gmr.15038989 
0.01 for Gata-3 compared to uninfected controls). Finally, infected mice generated significantly more Foxp3 compared with uninfected controls.
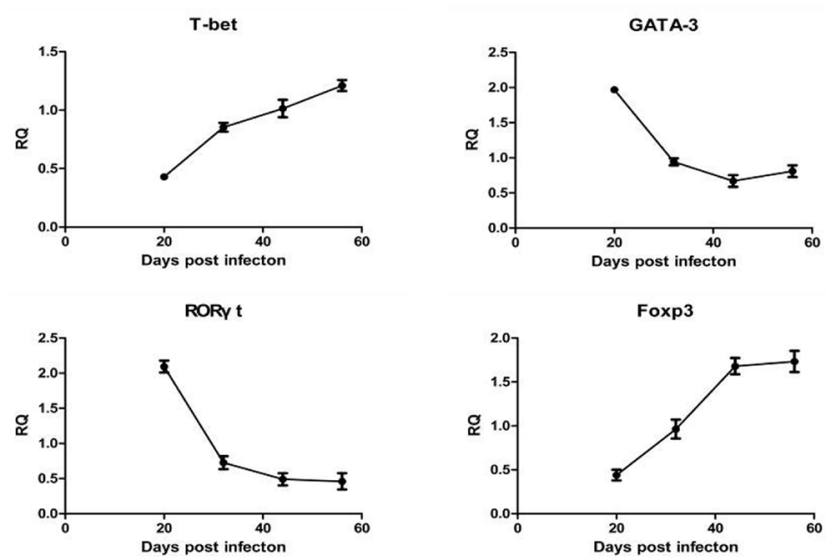

Figure 3. Expression of transcription factors from CD4+ T cell subsets in lung homogenates from infected mice. $\mathrm{RQ}=$ relative quantification of mRNA expression in infected versus uninfected mice.

\section{Changes in lung lymphocyte subsets}

To analyze M. neoaurum-specific immune response, immune cell subsets were evaluated. Examples of flow cytometric detection and gating of lung cells are shown in Figure 4A. Results indicated that $72 \%$ of CD4+ T cells, $20 \%$ of CD $8+$ T cells, and all CD3+ T cells appeared in the early days of infection. This was followed by a decrease to $47 \%$ for CD4+ T cells by day 32 , and then a rise to $76 \%$ by day 56 (Figure 4B). The opposite trend was observed for CD8+ cells (Figure 4B).

A
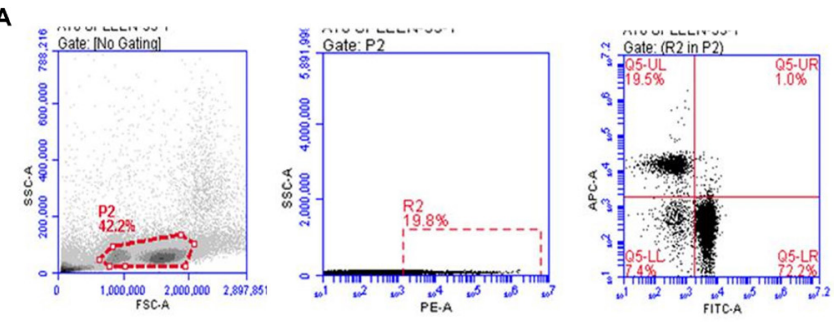

B

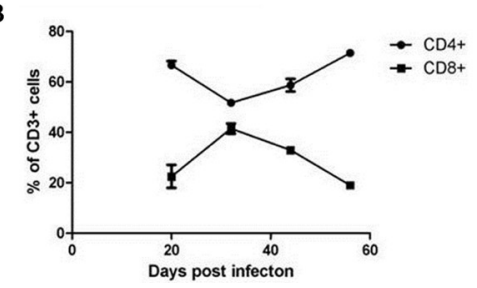

Figure 4. Development of adaptive T cell response during Mycobacterium neoaurum infection. A. Examples of flow cytometric gating and lymphocyte analysis. B. Phenotyping of lung T cell subsets during M. neoaurum infection: relative frequencies of $\mathrm{CD} 4+$ and $\mathrm{CD} 8+$ subsets within the $\mathrm{CD} 3+\mathrm{T}$ cell population.

Genetics and Molecular Research 15 (3): gmr.15038989 


\section{Changes to CD4+ T cell subsets in the lungs}

To better understand the effect of CD4+ T cell subsets on M. neoaurum pathogenesis, we used flow cytometry to analyze the proportion of CD4+ IFN- $\gamma+$ cells, CD4+ IL-4+ cells, and CD4+ IL-17+cells in the lungs. As shown in Figure 5, the level of CD4+ IFN- $\gamma+$ cells at day 20 post infection was significantly lower than that of uninfected mice $(\mathrm{P}<0.05)$, but increased gradually thereafter, surpassing it by day 56 . In contrast, the levels of CD4+ IL-4+ and CD4+ IL-17+ lymphocytes decreased substantially following M. neoaurum infection.
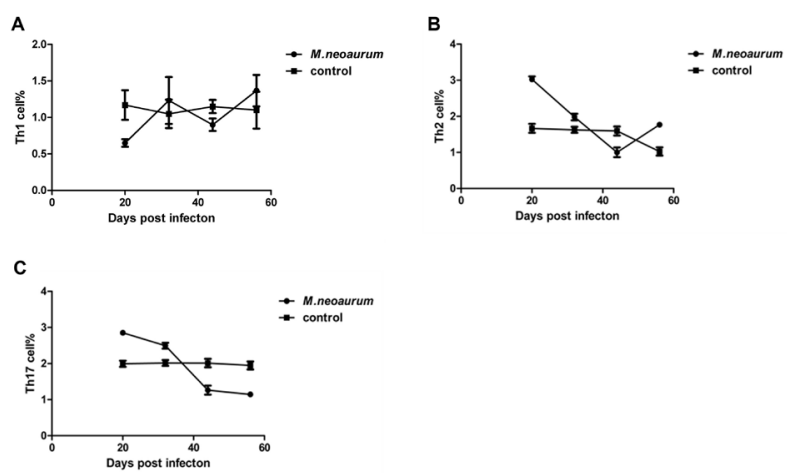

Figure 5. Percentages of CD4+ IFN- $\gamma+($ Th1) (A), CD4+ IL-4+ (Th2) (B), and CD4+ IL-17+ (Th17) (C) lymphocytes in Mycobacterium neoaurum infected mice and in uninfected mice.

\section{Frequency of CD4+ Foxp3+ Tregs in the lungs}

To further understand the T cell response, we examined the level of CD4+ Foxp3+ Tregs following $M$. neoaurum infection. Figure 6A shows the gating for CD4+ T cells expressing Foxp3+. We found a relative decrease in the number of CD4+ Foxp3+ Tregs between day 7 and 20 after M. neoaurum infection, followed by a small increase at day 32 (Figure 6B). Overall, though, there was no significant change in the number of Tregs between day 7 and day 56 post infection.
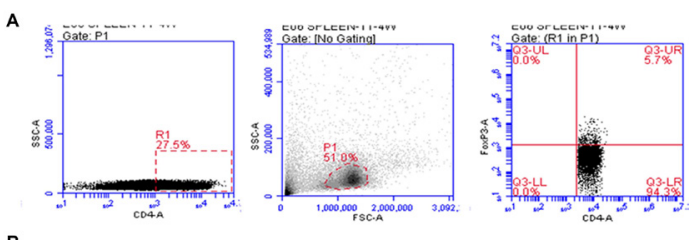

B

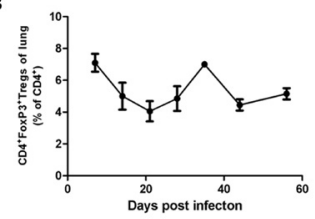

Figure 6. Relative frequency of lung CD4+ Foxp3+ Tregs in Mycobacterium neoaurum infected mice. A. Examples of gating and analysis of CD4+ Foxp3+ Treg cell. B. Relative frequency of Tregs in the lungs of mice during 56 days following $M$. neoaurum infection.

Genetics and Molecular Research 15 (3): gmr.15038989 


\section{DISCUSSION}

Over the past few years, researchers have invested vast efforts for understanding the immune mechanisms elicited by infection with M. tuberculosis, but not by NTM. In this study, we characterized the immune response of C57BL/6 mice infected with an animal isolate of M. neoaurum. Infected mice suffered from chronic infections in lung tissues, denoted by inflammatory cell infiltration and a strong $\mathrm{T}$ cell response. However, mice were surprisingly healthy and no clinical reaction, such as fever, weight loss, or discomfort, was observed for up to 18 weeks post infection. These findings indicate that infection with M. neoaurum lowers resistance to disease, but it remains to be seen whether it also facilitates secondary infections.

Many studies have reported that immunity to M. tuberculosis requires a Th1 response and mediation by IFN- $\gamma$ (Salgame, 2005; Cooper and Khader, 2008; Sutherland et al., 2009). As expected, we confirmed the apparent Th1 immune response elicited by infection with $M$. neoaurum, indicated by an increased number of $\mathrm{CD} 4+$ IFN- $\gamma+$ cells and relative mRNA expression of T-bet in the lungs of infected mice. These results are in agreement with those of Kawamura (2006), Salgame (2005), and Sutherland et al. (2009). Our results indicate that Th1 cells are important for the control of $M$. neoaurum infection and the host immune response to it.

IL-17 is an important cytokine in mycobacterial infection; it not only contributes to the formation of granulomas, but also controls bacterial growth (Khader et al., 2007; Cruz et al., 2010; Torrado and Cooper, 2010; Cowan et al., 2012). ROR $\gamma t$ was significantly induced at day 20 post infection, but decreased thereafter. A similar trend was observed in the case of Th17 (CD4+ IL-17+) cells. The latter may have been caused by the negative.

Foxp3+ Tregs are important for the immune response against M. tuberculosis, although their exact role is not yet completely clear. Some studies have indicated that Tregs promote the immunosuppressive activity of effector cells against intracellular pathogens (Shevach, 2009; Shafiani et al., 2010) during the early immune response. Although we observed a general increase in mRNA expression of Foxp3 in the lungs, this did not translate into a difference in overall Treg cell numbers at 56 days post infection. However, the number of Tregs in the lungs and spleen (not shown) decreased between 7 and 21 days after infection, which is in agreement with a previous study on M. avium infection (Haug et al., 2013). This phase may favor immune activation and inflammation rather than suppression, which may help contain the infection. At 21 days post infection, Treg cell numbers increased significantly while those of Th17 cells decreased, supporting the possibility that Foxp3, an indispensable transcription factor in Tregs, inhibited ROR $\gamma \mathrm{t}$ and blocked the differentiation of Th17 cells, as described by Zhou et al. (2008) and Ivanov et al., (2006). This hypothesis contrasts with our finding that the frequency of Tregs in the spleen was approximately two-fold higher than that in the lungs.

The present study provides significant characterization of the immune response in C57BL/6 mice infected with a clinical isolate of M. neoaurum. Moreover, we describe the relative contribution of Th1, Th17, and Treg cells to M. neoaurum infection. Our results may improve our understanding of mycobacterial infection and that of $M$. neoaurum in particular. This may, in turn, provide a solid basis for designing new vaccines and treatment schedules.

\section{Conflicts of interest}

The authors declare conflict of interest.

Genetics and Molecular Research 15 (3): gmr.15038989 


\title{
ACKNOWLEDGMENTS
}

\author{
Research supported by the National Natural Science Foundation of China (grant \\ \#31272566 and \#31302124).
}

\section{REFERENCES}

Arrazuria R, Sevilla IA, Molina E, Pérez V, et al. (2015). Detection of Mycobacterium avium subspecies in the gut associated lymphoid tissue of slaughtered rabbits. BMC Vet. Res. 11: 130. http://dx.doi.org/10.1186/s12917-015$\underline{0445-2}$

Chen CY, Huang D, Yao S, Halliday L, et al. (2012). IL-2 simultaneously expands Foxp3+ T regulatory and T effector cells and confers resistance to severe tuberculosis (TB): implicative Treg-T effector cooperation in immunity to TB. J. Immunol. 188: 4278-4288. http://dx.doi.org/10.4049/jimmunol.1101291

Cooper AM (2010). Editorial: Be careful what you ask for: is the presence of IL-17 indicative of immunity? J. Leukoc. Biol. 88: 221-223.http://dx.doi.org/10.1189/jlb.0310146

Cooper AM and Khader SA (2008). The role of cytokines in the initiation, expansion, and control of cellular immunity to tuberculosis. Immunol. Rev. 226: 191-204. http://dx.doi.org/10.1111/j.1600-065X.2008.00702.x

Cowan J, Pandey S, Filion LG, Angel JB, et al. (2012). Comparison of interferon-g-, interleukin (IL)-17- and IL-22expressing CD4 T cells, IL-22-expressing granulocytes and proinflammatory cytokines during latent and active tuberculosis infection. Clin. Exp. Immunol. 167: 317-329. http://dx.doi.org/10.1111/j.1365-2249.2011.04520.x

Cruz A, Fraga AG, Fountain JJ, Rangel-Moreno J, et al. (2010). Pathological role of interleukin 17 in mice subjected to repeated BCG vaccination after infection with Mycobacterium tuberculosis. J. Exp. Med. 207: 1609-1616. http:// dx.doi.org/10.1084/jem.20100265

Flynn JL, Chan J, Triebold KJ, Dalton DK, et al. (1993). An essential role for interferon gamma in resistance to Mycobacterium tuberculosis infection. J. Exp. Med. 178: 2249-2254. http://dx.doi.org/10.1084/jem.178.6.2249

Fowler J and Mahlen SD (2014). Localized cutaneous infections in immunocompetent individuals due to rapidly growing mycobacteria. Arch. Pathol. Lab. Med. 138: 1106-1109. http://dx.doi.org/10.5858/arpa.2012-0203-RS

Gcebe N, Rutten V, van Pittius NC and Michel A (2013). Prevalence and distribution of non-tuberculous mycobacteria (NTM) in cattle, African buffaloes (Syncerus caffer) and their environments in South Africa. Transbound. Emerg. Dis. 60 (Suppl 1): 74-84. http://dx.doi.org/10.1111/tbed.12133

Goldsack L and Kirman JR (2007). Half-truths and selective memory: Interferon gamma, CD4(+) T cells and protective memory against tuberculosis. Tuberculosis 87: 465-473. http://dx.doi.org/10.1016/j.tube.2007.07.001

Griffith DE, Aksamit T, Brown-Elliott BA, Catanzaro A, et al.; ATS Mycobacterial Diseases Subcommittee; American Thoracic Society; Infectious Disease Society of America (2007). An official ATS/IDSA statement: diagnosis, treatment, and prevention of nontuberculous mycobacterial diseases. Am. J. Respir. Crit. Care Med. 175: 367-416. http://dx.doi.org/10.1164/rccm.200604-571ST

Haug M, Awuh JA, Steigedal M, Frengen Kojen J, et al. (2013). Dynamics of immune effector mechanisms during infection with Mycobacterium avium in C57BL/6 mice. Immunology 140: 232-243. http://dx.doi.org/10.1111/imm.12131

Henkle E and Winthrop KL (2015). Nontuberculous mycobacteria infections in immunosuppressed hosts. Clin. Chest Med. 36: 91-99. http://dx.doi.org/10.1016/j.ccm.2014.11.002

Ivanov II, McKenzie BS, Zhou L, Tadokoro CE, et al. (2006). The orphan nuclear receptor RORgammat directs the differentiation program of proinflammatory IL-17+ T helper cells. Cell 126: 1121-1133. http://dx.doi.org/10.1016/j. cell.2006.07.035

Kawamura I (2006). Protective immunity against Mycobacterium tuberculosis. Kekkaku 81: 687-691.

Kazda J, Pavlik I, Falkinham JO and Hruska K (2009).The ecology of mycobacteria: Impact on animal's and human's health. 1st edn. Springer, Heidelberg.

Khader SA, Bell GK, Pearl JE, Fountain JJ, et al. (2007). IL-23 and IL-17 in the establishment of protective pulmonary CD4+ T cell responses after vaccination and during Mycobacterium tuberculosis challenge. Nat. Immunol. 8: 369377. http://dx.doi.org/10.1038/ni1449

Kim BR, Kim JM, Kim BJ, Jang Y, et al. (2014). Identification of nontuberculous mycobacteria isolated from Hanwoo (Bos taurus coreanae) in South Korea by sequencing analysis targeting hsp65, rpoB and 16S rRNA genes. Vet. Microbiol. 173: 385-389. http://dx.doi.org/10.1016/j.vetmic.2014.07.019

Kolls JK and Lindén A (2004). Interleukin-17 family members and inflammation. Immunity 21: 467-476. http://dx.doi. org/10.1016/j.immuni.2004.08.018

Genetics and Molecular Research 15 (3): gmr.15038989 
Larson RP, Shafiani S and Urdahl KB (2013). Foxp3(+) regulatory T cells in tuberculosis. Adv. Exp. Med. Biol. 783: 165180. http://dx.doi.org/10.1007/978-1-4614-6111-1_9

Newport MJ, Huxley CM, Huston S, Hawrylowicz CM, et al. (1996). A mutation in the interferon-gamma-receptor gene and susceptibility to mycobacterial infection. N. Engl. J. Med. 335: 1941-1949. http://dx.doi.org/10.1056/ NEJM199612263352602

Ristola M, Arbeit RD, von Reyn CF and Horsburgh CR, Jr. (2015). Isolation of Mycobacterium avium from potable water in homes and institutions of patients with HIV infection in Finland and the United States. BioMed Res. Int. 2015: 713845. http://dx.doi.org/10.1155/2015/713845

Sakaguchi S, Miyara M, Costantino CM and Hafler DA (2010). FOXP3+ regulatory T cells in the human immune system. Nat. Rev. Immunol. 10: 490-500. http://dx.doi.org/10.1038/nri2785

Salgame P (2005). Host innate and Th1 responses and the bacterial factors that control Mycobacterium tuberculosis infection. Curr. Opin. Immunol. 17: 374-380. http://dx.doi.org/10.1016/j.coi.2005.06.006

Shafiani S, Tucker-Heard G, Kariyone A, Takatsu K, et al. (2010). Pathogen-specific regulatory T cells delay the arrival of effector T cells in the lung during early tuberculosis. J. Exp. Med. 207: 1409-1420. http://dx.doi.org/10.1084/ jem.20091885

Shevach EM (2009). Mechanisms of foxp3+ T regulatory cell-mediated suppression. Immunity 30: 636-645.http://dx.doi. org/10.1016/j.immuni.2009.04.010

Sutherland JS, Adetifa IM, Hill PC, Adegbola RA, et al. (2009). Pattern and diversity of cytokine production differentiates between Mycobacterium tuberculosis infection and disease. Eur. J. Immunol. 39: 723-729. http://dx.doi.org/10.1002/ eji. 200838693

Torrado E and Cooper AM (2010). IL-17 and Th17 cells in tuberculosis. Cytokine Growth Factor Rev. 21: 455-462. http:// dx.doi.org/10.1016/j.cytogfr.2010.10.004

Umehara T, Aoki M, Harada A, Watanabe Y, et al. (2015). A Case of Nontuberculous Mycobacteria Highly Suspected as Lung Cancer Invading the Aortic Arch. J. Thorac. Oncol. 10: 1118-1119. http://dx.doi.org/10.1097/ $\underline{\text { JTO.0000000000000413 }}$

Zhou L, Lopes JE, Chong MM, Ivanov II, et al. (2008). TGF-beta-induced Foxp3 inhibits T(H)17 cell differentiation by antagonizing RORgammat function. Nature 453: 236-240. http://dx.doi.org/10.1038/nature06878

Genetics and Molecular Research 15 (3): gmr.15038989 